\title{
Effective uptake of submicrometre plastics by crop plants via a crack-entry mode
}

\author{
Lianzhen Li 1,2, Yongming Luo $\circledast^{1,2,3 凶, ~ R u i j i e ~ L i ', ~ Q i a n ~ Z h o u ', ~ W i l l i e ~ J . ~ G . ~ M . ~ P e i j n e n b u r g, ~}{ }^{4,5}$, Na Yin', \\ Jie Yang ${ }^{3}$, Chen Tu ${ }^{1,2}$ and Yunchao Zhang ${ }^{1}$
}

\begin{abstract}
Most microplastics are emitted, either directly or via the degradation of plastics, to the terrestrial environment and accumulate in large amounts in soils, representing a potential threat to terrestrial ecosystems. It is very important to evaluate the uptake of microplastics by crop plants because of the ubiquity of microplastics in wastewaters often used for agricultural irrigation worldwide. Here, we analyse the uptake of different microplastics by crop plants (wheat (Triticum aestivum) and lettuce (Lactuca sativa)) from treated wastewater in hydroponic cultures and in sand matrices or a sandy soil. Our results provide evidence in support of submicrometre- and micrometre-sized polystyrene and polymethylmethacrylate particles penetrating the stele of both species using the crack-entry mode at sites of lateral root emergence. This crack-entry pathway and features of the polymeric particles lead to the efficient uptake of submicrometre plastic. The plastic particles were subsequently transported from the roots to the shoots. Higher transpiration rates enhanced the uptake of plastic particles, showing that the transpirational pull was the main driving force of their movement. Our findings shed light on the modes of plastic particle interaction with plants and have implications for crops grown in fields contaminated with wastewater treatment discharges or sewage sludges.
\end{abstract}

A pproximately 330 million tons of plastic were produced worldwide in 2015, and this figure continues to increase ${ }^{1}$. As a result, the contamination of our environment with plastics of all sizes is becoming one of the most widespread and long-lasting anthropogenic changes to the biosphere of our planet ${ }^{2}$. Microplastics (MPs) are generally defined as plastic particles in the size range of $100 \mathrm{~nm}$ to $5 \mathrm{~mm}$, including submicrometre $(100 \mathrm{~nm}$ to $1 \mu \mathrm{m})$ and micrometre $(1 \mu \mathrm{m}$ to $5 \mathrm{~mm})$ plastics, and nanoplastics ranging from $1 \mathrm{~nm}$ to $100 \mathrm{~nm}$ (ref. ${ }^{3}$ ). Furthermore, MPs are separated into primary MPs, which are originally manufactured in a particularly small size for specific applications, and secondary MPs, originating from the fragmentation of larger plastic debris by external forces ${ }^{3}$.

Scientific research on MPs pollution is rapidly advancing. However, studies to date have focused almost exclusively on aquatic systems, especially the oceans ${ }^{4-6}$. The oceans represent the ultimate sink for most MPs, but the terrestrial environment is a major recipient of plastics of all sizes, owing to the large amounts of anthropogenic wastes derived from sewage sludges, organic fertilizers, plastic mulching, wastewater irrigation and other sources such as atmospheric particulate deposition ${ }^{7-9}$. On the basis of emissions data, it is estimated that 110,000 and 730,000 tons of MPs are added annually to farmlands in Europe and North America, respectively ${ }^{10}$. These figures exceed the estimated annual global burden of MPs in ocean surface waters of $93,000-236,000$ tons $^{11}$. Hence, there is a great need to understand and quantify the distribution, fate and transformation of MPs in the terrestrial compartment.

Very little information exists on the accumulation and effects of MPs on soil biota ${ }^{12,13}$. Plants comprise a basic living component of terrestrial ecosystems and are an important source of human food. Thus, understanding the interactions between MPs and plants is crucial. Given the central role of agroecosystems in food production and the tight connection with soil biodiversity, the accumulation of MPs in the terrestrial environment provides various potential pathways for the exposure of humans and biota to MPs and might induce adverse effects on organisms (including food crops) and human health ${ }^{4,5}$. Understanding the interactions of MPs with plants, particularly food plants, is thus a crucial aspect of risk assessment for these materials. In addition, the use of treated wastewater for irrigation is increasing worldwide and is not limited to arid zones ${ }^{14}$. Considering the ubiquity of plastic beads in treated wastewater ${ }^{15}$, it is important to evaluate their uptake by edible crops under natural conditions.

Despite the large body of literature on the apoplastic uptake of nanomaterials ${ }^{16}$, it has been assumed that MPs are too large to pass through the physical barriers of intact plant tissue and hence cannot be internalized directly into plant tissue. The Casparian band of the root endodermis is believed to function as a barrier to the apoplastic movement of chemicals and water into the root stele. However, there are known to be discontinuous regions in the Casparian band in roots, through which unhindered transport in the apoplast might occur. Such regions are found at the root tip where the endodermal cells are not yet mature ${ }^{17}$ and at the sites of secondary root initiation $^{18}$. Given that such openings are a known pathway of infection by plant pathogens or bacteria (with submicrometre widths, and lengths variable to several micrometres), known as the crack-entry mode ${ }^{19,20}$, we hypothesized that these openings might provide routes for plastic particle uptake.

Here, we aim to determine whether wheat and lettuce growing in hydroponic systems and sand matrices or a sandy soil are able to take up submicrometre- to micrometre-sized plastic beads from either a nutrient solution or treated wastewater and translocate

'CAS Key Laboratory of Coastal Environmental Processes and Ecological Remediation, Yantai Institute of Coastal Zone Research, Chinese Academy of Sciences, Yantai, China. ${ }^{2}$ Center for Ocean Mega-Science, Chinese Academy of Sciences, Qingdao, China. ${ }^{3}$ CAS Key Laboratory of Soil Environment and Pollution Remediation, Institute of Soil Science, Chinese Academy of Sciences, Nanjing, China. ${ }^{4}$ Center for Safety of Substances and Products, National Institute of Public Health and the Environment, Bilthoven, The Netherlands. Institute of Environmental Sciences (CML), Leiden University, Leiden,

The Netherlands. e-mail: ymluo@issas.ac.cn 

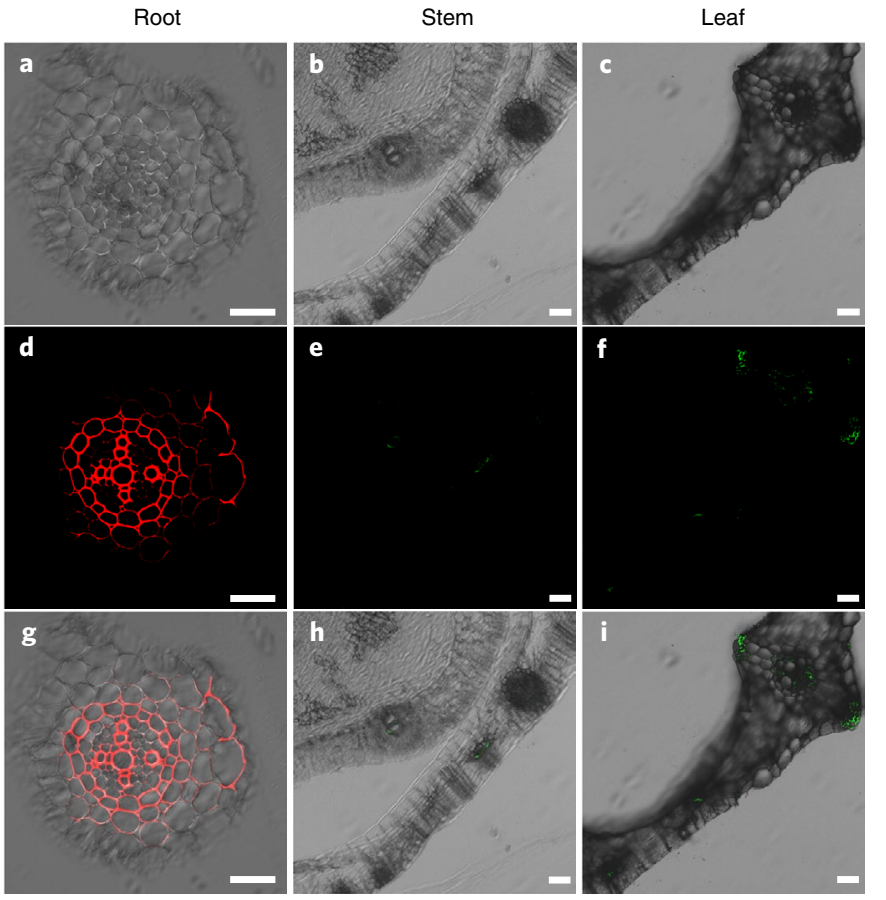

Fig. 1 | Accumulation of $0.2 \mu \mathrm{m}$ fluorescently labelled PS beads by wheat plants. Two-week-old plants were exposed to $50 \mathrm{mg} \mathrm{l}^{-1}$ suspensions of PS beads labelled with NB and PS beads labelled with NBD-Cl for $10 \mathrm{~d}$. The uptake of PS beads by wheat roots, stems and leaves was analysed under bright field conditions and in red/green channels using confocal laser scanning microscopy. a-c, Bright field images showing transverse sections of a root (a), a stem (b) and a leaf (c) from a whole wheat plant treated with PS beads labelled with NB and PS beads labelled with NBD-Cl. $\mathbf{d}-\mathbf{f}$, Images of wheat root (d), stem (e) and leaf (f) transverse sections observed using either the red or green channel to detect NB or NBD-Cl, respectively. $\mathbf{d}$, Observation of aggregates of PS beads labelled with NB in the intercellular spaces of the epidermis and xylem and the flow of PS beads labelled with NB towards the cortex. e, PS beads labelled with NBD-Cl observed in the vascular tissue of the stem. $\mathbf{f}$, The accumulation of the fluorescent aggregates in the xylem and associated cells in the vascular tissue of the leaf. $\mathbf{g}-\mathbf{i}$, The corresponding merged images of $\mathbf{a}$ and $\mathbf{d}(\mathbf{g}), \mathbf{b}$ and $\mathbf{e}(\mathbf{h})$, and $\mathbf{c}$ and $\mathbf{f}(\mathbf{i})$. Scale bars, $50 \mu \mathrm{m}$.

these particles from roots to shoots, and if so, to identify the uptake sites and pathways. Wheat was chosen as a representative of monocot plants because it is one of the main staple foods worldwide; lettuce was selected as a representative of dicot plants because it is a popular leafy vegetable.

\section{Polystyrene beads penetrating the stele via a crack-entry mode}

Two fluorescent dyes were used to detect the presence of plastic beads because the red fluorescence from Nile blue (NB) is indistinguishable from the autofluorescence emitted by chloroplasts, and the green fluorescence from 4-chloro-7-nitro-1,2,3-benzoxadiazole (NBD-Cl) is indistinguishable from the autofluorescence in root tissues of wheat and lettuce plants (Supplementary Figs. 1 and 2). Sections from untreated control wheat and lettuce plants showed no detectable autofluorescence at specific excitation wavelengths (Supplementary Fig. 3). The roots of wheat grown in a Hoagland solution containing $0.2 \mu \mathrm{m}$ polystyrene (PS) beads showed clear concentration-dependent fluorescence (Supplementary Fig. 4). Fluorescence was observed in the roots, shoots and leaves of wheat and lettuce exposed to $0.2 \mu \mathrm{m}$ PS beads (Figs. 1 and 2) and in the roots of wheat and lettuce exposed to $2.0 \mu \mathrm{m}$ PS beads (Supplementary Fig. 5). Very few luminescence signals were observed in the vascular system or in the epidermis of wheat and lettuce roots for $5.0 \mu \mathrm{m}$ and almost none for $7.0 \mu \mathrm{m}$ and $10 \mu \mathrm{m}$ PS microbeads (Supplementary Fig. 6). Our main study investigated the uptake of submicrometre-sized $(0.2 \mu \mathrm{m})$ and micrometre-sized $(2.0 \mu \mathrm{m})$ plastic beads to explore the underlying mechanisms involved in plastic bead uptake and transport.

After attaching to the border cells, submicrometre PS beads $(0.2 \mu \mathrm{m})$ were observed along the entire lateral root cap and within the apical meristem of wheat and lettuce roots (Supplementary Figs. 7 and 8). We suggest that the entrapment of PS beads in the root cap mucilage promoted their penetration of the cell wall, enabling diffusion through the apical meristem tissue, which is highly porous because of active cell division ${ }^{21}$. However, cell wall pores $(3.5-5.0 \mathrm{~nm})^{22}$ and intercellular plasmodesmata $(50-60 \mathrm{~nm}$ at the midpoint $)^{23}$ have diameters that are smaller than the $0.2 \mu \mathrm{m}$ diameter of the PS beads used in this study. We therefore suggest that PS beads can enter the apical meristem only by passing through the epidermal layers of the intact apical root sections, where the Casparian band is not fully developed ${ }^{21}$. The PS beads then diffuse across the apoplastic spaces in the apical zone into the root xylem vessels, which facilitated their rapid transport in wheat roots (Supplementary Fig. 9). Confocal images of the transverse sections of wheat revealed that the PS luminescence signals were located mainly in the vascular system of the roots and stems (Fig. 1) and were visible in the xylem vessels and epidermis after $2 \mathrm{~h}$ (Supplementary Fig. 10). After $12 \mathrm{~h}$, PS beads were detected in the wheat cortical tissue (Supplementary Fig. 10), whereas in lettuce plants, they appeared to be more restricted to the vascular tissues (Fig. 2 and Supplementary Fig. 11). Fluorescence was observed mainly along cell walls and in the intercellular region, indicating that $0.2 \mu \mathrm{m}$ PS beads entered the cortical region through gaps between epidermal cells but were not able to penetrate the endodermis in regions where the Casparian band was continuous. A strong PS luminescence signal was detected in cracks in the lateral root zone $(50-100 \mathrm{~mm}$ from the apex) (Supplementary Fig. 11), where the lateral roots penetrate the endodermis and the cortex, indicating that these cracks were major entry sites into the wheat and lettuce root xylem for submicrometre PS beads. The physical sites of the apoplasmic bypass were located not only in regions where lateral roots emerge but also in the lateral roots themselves. This is supported by the observation of beads penetrating into the xylem of lateral roots as well as their presence in the primary roots of wheat and lettuce (Supplementary Fig. 11e,f).

In contrast to the $0.2 \mu \mathrm{m}$ PS beads, micrometre-sized PS beads $(2.0 \mu \mathrm{m})$ penetrated the stele only when a secondary root that had just emerged through the epidermis of the main root was present (Supplementary Fig. 4), consistent with observations that $2.0 \mu \mathrm{m}$ microbeads were not present in the entire wheat roots lacking secondaries (Supplementary Fig. 12). Lateral root formation occurs deep within the primary root. To allow lateral root primordia to emerge, the overlying tissues undergo cell separation, resulting in gaps between the epidermal cells at sites of lateral root emergence. We visualized these gaps in lettuce and wheat roots by performing scanning electron microscopy (SEM) (Supplementary Fig. 13) and by scanning root samples using a high-resolution X-ray computed microtomography system to construct three-dimensional images of wheat roots (Supplementary Fig. 14). Confocal images of longitudinal sections through a recently emerged secondary wheat root revealed that the luminescence signals from $0.2 \mu \mathrm{m}$ PS beads were visible in the xylem vessels and cortical tissue after $30 \mathrm{~min}$ (Supplementary Fig. 15), whereas $2.0 \mu \mathrm{m}$ PS beads were first detected in the epidermis and vascular tissues of wheat after $48 \mathrm{~h}$ (Supplementary Fig. 15). After $12 \mathrm{~h}$, strong luminescence signals from the $0.2 \mu \mathrm{m}$ PS beads were observed in the stele of the secondary 

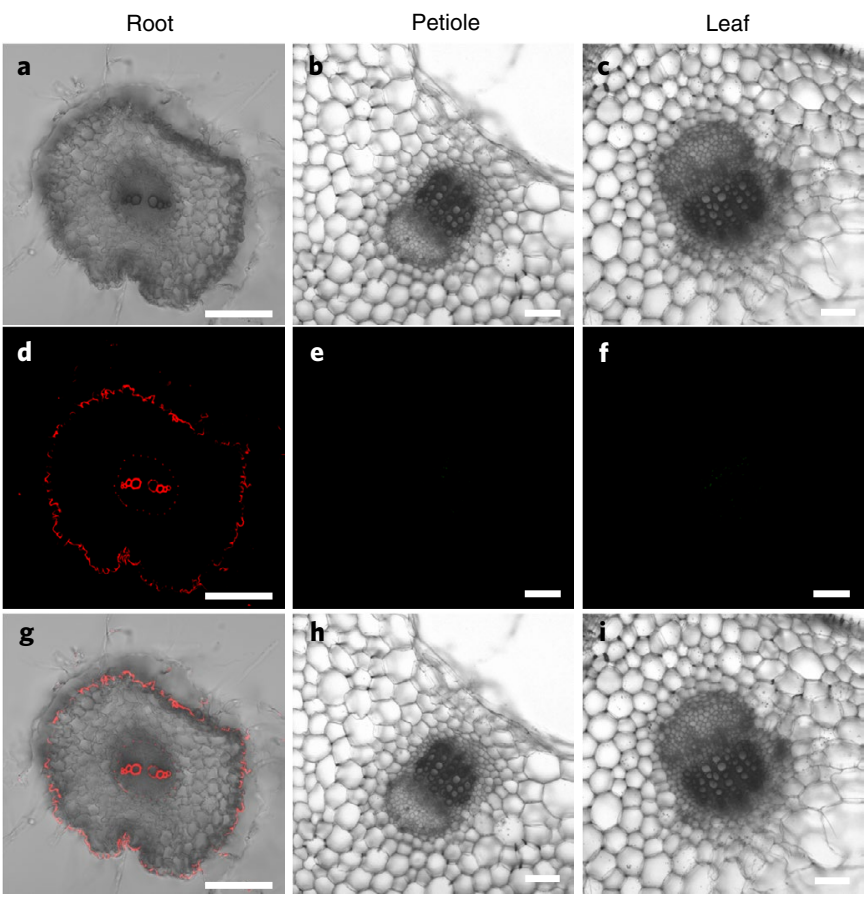

Fig. 2 | Accumulation of $0.2 \mu \mathrm{m}$ fluorescently labelled PS beads by lettuce. One-month-old plants were exposed to $50 \mathrm{mg} \mathrm{l}^{-1}$ suspensions of PS beads labelled with NB and PS beads labelled with NBD-Cl for $10 \mathrm{~d}$. The uptake of PS beads by lettuce roots, petioles and leaves was analysed under bright field conditions and in red/green channels using confocal laser scanning microscopy. a-c, Bright field images showing transverse sections of a lettuce root (a), a petiole (b) and a leaf (c) treated with PS beads labelled with NB or PS beads labelled with NBD-Cl. d-f, Images of lettuce root (d), petiole (e) and leaf (f) transverse sections observed in the red or green channel to detect NB or NBD-Cl, respectively. d, Aggregates of fluorescently labelled PS beads labelled with NB in the epidermis and xylem. e,f, Fluorescent beads in the vascular tissue of the petiole and leaf, respectively. $\mathbf{g}-\mathbf{i}$, The corresponding merged images of $\mathbf{a}$ and $\mathbf{d}(\mathbf{g}), \mathbf{b}$ and $\mathbf{e}$ (h), and $\mathbf{c}$ and $\mathbf{f}(\mathbf{i})$. Scale bars, $100 \mu \mathrm{m}$.

root (Supplementary Fig. 15). We hypothesize that these beads entered this region via the lateral root apex. In most cases, $2 \mu \mathrm{m}$ PS microbeads were not present in the lateral roots; however, they were observed in the main root stele after moving along the margins of the secondary root and through the region occupied by cells in the transition zone, which are cells derived from the endodermis of the main root that are transitioning between the endodermis of the main root and the epidermis of the secondary $\operatorname{root}^{18}$. Here, an entry mode for the PS beads was detected in which even the micrometre-sized $(2.0 \mu \mathrm{m})$ beads penetrated the stele via cracks in the epidermis that initiate lateral root formation.

From SEM images, the aggregation of $0.2 \mu \mathrm{m}$ PS beads was mostly in the xylem and on the cell walls of the cortex tissue in wheat and lettuce roots, indicating that the beads passed through the intercellular space via the apoplastic transport system (Figs. 3 and 4). Micrometre-sized beads were visible in the gaps between the epidermal cells of the main wheat root and the secondary root (Fig. 5). We also observed that the $0.2 \mu \mathrm{m}$ PS beads adhered to one another and self-assembled systematically into grape-like (Fig. 4a) and string-like (Fig. 4b) clusters in the intercellular space of the lettuce root and stem vascular tissue. In contrast to the aggregation of $0.2 \mu \mathrm{m}$ PS beads, micrometre-sized PS beads were dispersed in the tissue of lettuce plants (Fig. 6) and were visible in the crack between the epidermal tissue of the main wheat root and the secondary root
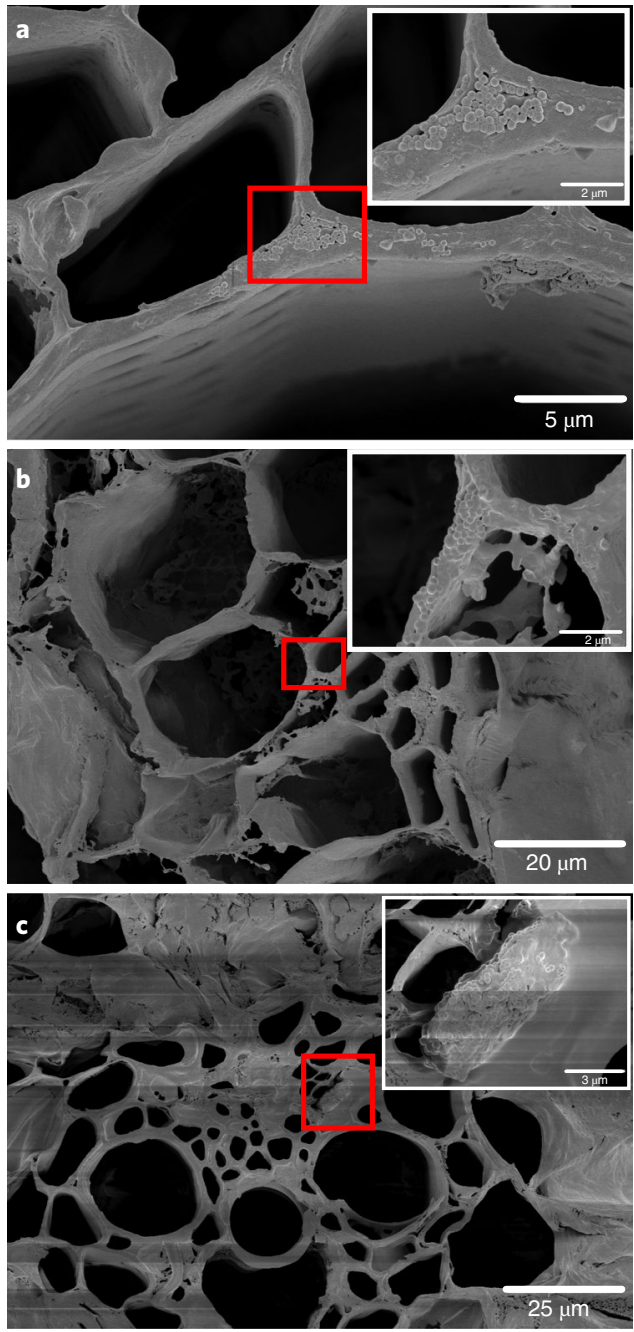

Fig. 3 | SEM images of $0.2 \mu \mathrm{m}$ PS bead localization in the root, stem and leaf of a wheat plant. Two-week-old plants were exposed to $50 \mathrm{mg} \mathrm{l}^{-1}$ suspensions of PS beads for $10 \mathrm{~d}$. a, PS beads deformed and squeezed into the intercellular space of the vascular tissue of the root. $\mathbf{b}$, Aggregated clumps of PS beads on the outer side of the cell wall in the stem xylem. $\mathbf{c}$, PS beads were observed to associate with other cellular materials in the leaf vein. The insets show enlargements of the areas indicated by the red squares.

(Fig. 5a,b) and thereby moved through the pericycle and into the xylem (Fig. 5c,d).

Once inside the central cylinder, particles can move towards the aerial parts of a plant through the xylem, following the transpiration stream. The $0.2 \mu \mathrm{m}$ and $2.0 \mu \mathrm{m}$ beads were present in the xylem sap (Supplementary Fig. 16) of wheat and lettuce exposed to a $50 \mathrm{mgl}^{-1}$ suspension of PS beads, showing that both submicrometre-sized and micrometre-sized plastic beads were transported from roots to shoots via the transpiration stream. The fluorescence intensity was stronger at the junction of the primary root and the secondary root in wheat under high transpiration conditions than under low transpiration conditions (Supplementary Figs. 15 and 17), demonstrating that an increase in the transpiration rate enhances bead uptake by the plant. This finding suggests that the plant transpirational pull plays an important role in the uptake and translocation of plastic beads.

We also grew plants in a sand matrix or a sandy soil with different concentrations of PS beads. Sand was used as a proxy for soil because plants grown in sand develop similar root morphologies 

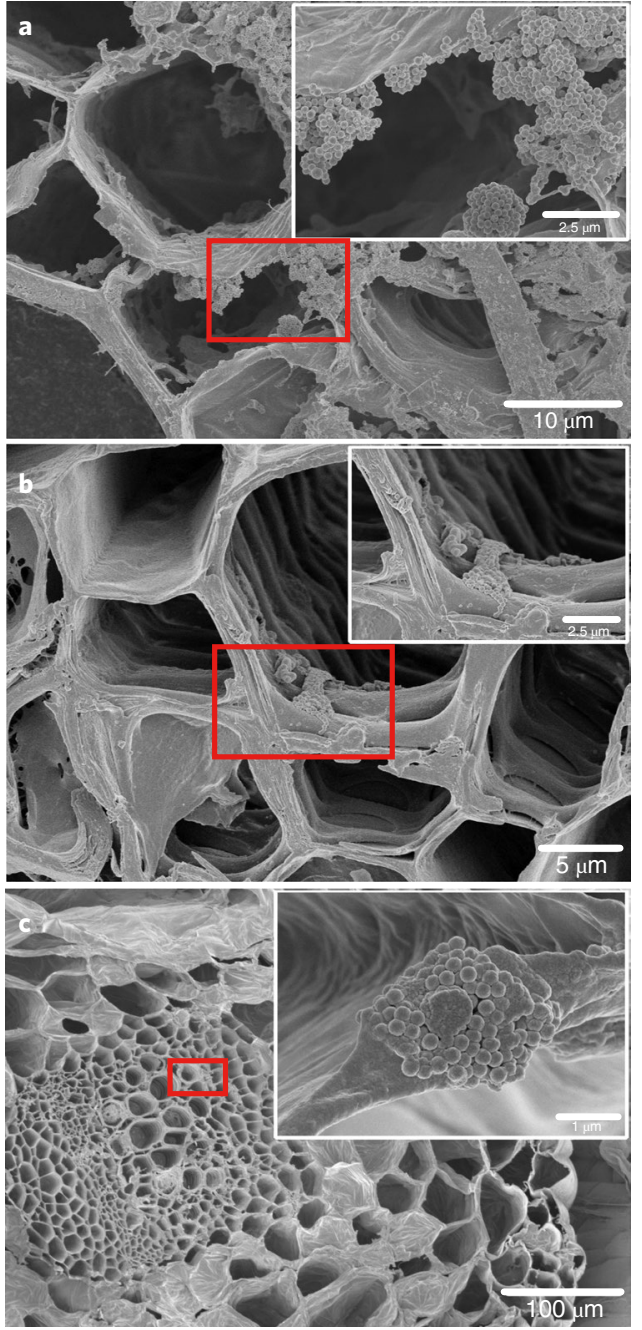

Fig. 4 | SEM images of $0.2 \mu \mathrm{m}$ PS bead localization in the root and leaf of a lettuce plant. One-month-old plants were exposed to $50 \mathrm{mg} \mathrm{l}^{-1}$ suspensions of PS beads for $10 \mathrm{~d}$. $\mathbf{a}, \mathbf{b}$, Beads were detected as systematically aggregated clumps in a grape-like or chain-like shape in lettuce roots. c, PS beads were observed to associate with other cellular materials in the leaf veins of lettuce plants. The insets show enlargements of the areas indicated by the red squares.

as plants grown in soil. Furthermore, the mechanical impedance and water stress experienced by plants growing in sand and soil are similar. Both submicrometre $(0.2 \mu \mathrm{m})$ and micrometre-sized $(2.0 \mu \mathrm{m})$ PS beads can be seen to enter the xylem vessels at the lateral root emergence sites (Supplementary Figs. 18-20) in sand cultures and were also present in the xylem sap of wheat and lettuce (Supplementary Fig. 21). The accumulation of $0.2 \mu \mathrm{m}$ fluorescently labelled PS beads was observed in the roots of wheat grown for 20 days with $500 \mathrm{mg} \mathrm{kg}^{-1}$ of beads in a sandy soil (Supplementary Fig. 18). Nevertheless, after solid exposure we did not detect the entry of $0.2 \mu \mathrm{m}$ beads into the steles from the root apex as observed in hydroponic exposure. Compared with the solid culture, the hydroponic culture depressed root apoplastic barrier formation to increase oxygen delivery to the stele from the cortical aerenchyma ${ }^{24}$, which would facilitate the transport of plastic beads passing through the apoplastic barriers at the root tip. Furthermore, plants grown hydroponically had higher growth rates and thus higher transpiration rates, thereby providing a stronger driving force for the apoplastic translocation of beads.

\section{Uptake and transfer of plastic beads from treated wastewater}

Polymethylmethacrylate (PMMA) is among the most commonly used plastic types as beads in cosmetics in Europe and in other countries $^{25,26}$. PMMA beads are likely to be transported to wastewater treatment plants. It is anticipated that a substantial proportion will pass through filtration systems due to their small size, and subsequently enter the environment ${ }^{27}$. The uptake of PMMA beads was evaluated in treated wastewater using lettuce plants. Confocal microscopic images demonstrate that PMMA $(0.2 \mu \mathrm{m})$ fluorescence was observed in the epidermis as well as in the vascular systems of different root zones (Supplementary Fig. 22). However, a much higher intensity of fluorescence appeared at the primary rootlateral root junction of lateral root emerging sites than in other regions (Supplementary Fig. 22). Fluorescence from 2.0 $\mu \mathrm{m}$ PMMA microbeads was located mainly at the lateral root emerging sites (Supplementary Fig. 23). The fluorescence was also observed in the intercellular space in lettuce leaf veins (Supplementary Fig. 24). The fluorescence patterns of these plastic beads in treated wastewater were similar to the patterns of PS beads in the nutrient solution. Furthermore, the fluorescence was more intense in plants under high transpiration regimes than in plants under low transpiration regimes in treated wastewater (Supplementary Figs. 22-24), verifying that an increase of the transpiration rate enhances the uptake of PMMA beads from treated wastewater by lettuce. This confirms that a higher temperature and lower humidity result in greater transpiration rates and thus an increased accumulation of beads of different polymer types in the root and upper portions of lettuce. On the basis of this finding, we hypothesize that in arid and hot climates where irrigation with treated wastewater is common, submicrometre plastic beads in wastewater may have a greater tendency to accumulate in crop plants due to the relatively high plant transpiration rates. Subsequent SEM observations showed that no beads can be found around the root and leaf veins in the control group without plastic bead treatments (data not shown). However, SEM images of cross sections in the root tissue clearly showed the presence of $0.2 \mu \mathrm{m}$ PMMA beads that were agglomerated and formed relatively larger clusters in the intercellular space of the vascular system as well as in the primary root-lateral root junction areas (Supplementary Fig. 25). Distinct from the $0.2 \mu \mathrm{m}$ PMMA beads, the $2.0 \mu \mathrm{m}$ beads were observed as single particles in the xylem vessels and the crack between the epidermal tissue of the primary lettuce root and the secondary root (Supplementary Fig. 26). The PMMA beads and their aggregates were also observed in the epidermis of lettuce roots (Supplementary Figs. 25 and 26). The presence of PMMA beads in the leaf vein (Supplementary Figs. 25 and 26) demonstrated the transfer of beads from the root to the shoot in lettuce.

Wheat plants were further studied in sand matrices irrigated with treated wastewater spiked with PS beads. Confocal microscopic images showed that both submicrometre $(0.2 \mu \mathrm{m})$ and micrometre-sized $(2.0 \mu \mathrm{m})$ PS beads enter the xylem vessels at the lateral root emergence sites of wheat (Supplementary Figs. 27 and 28). However, the $2.0 \mu \mathrm{m}$ PS beads could not enter the epidermis or the cortex in the root apex. SEM studies revealed that PS beads were present in the root vascular systems and at the primary root-lateral root junction (Supplementary Fig. 29). Both sizes of beads were also detected in the xylem sap of wheat (Supplementary Fig. 30), indicating that PS beads transfer from the roots to the shoot via the vascular system.

\section{Features of polymeric beads for their uptake and transfer}

For uptake and translocation in plants, particulate matter must cross a series of chemical and physiological barriers, which control the size exclusion limits (SELs). The thickness and architecture of these barriers vary with species, growth stages and environmental conditions ${ }^{28}$. It is generally accepted that very large nanoparticles 

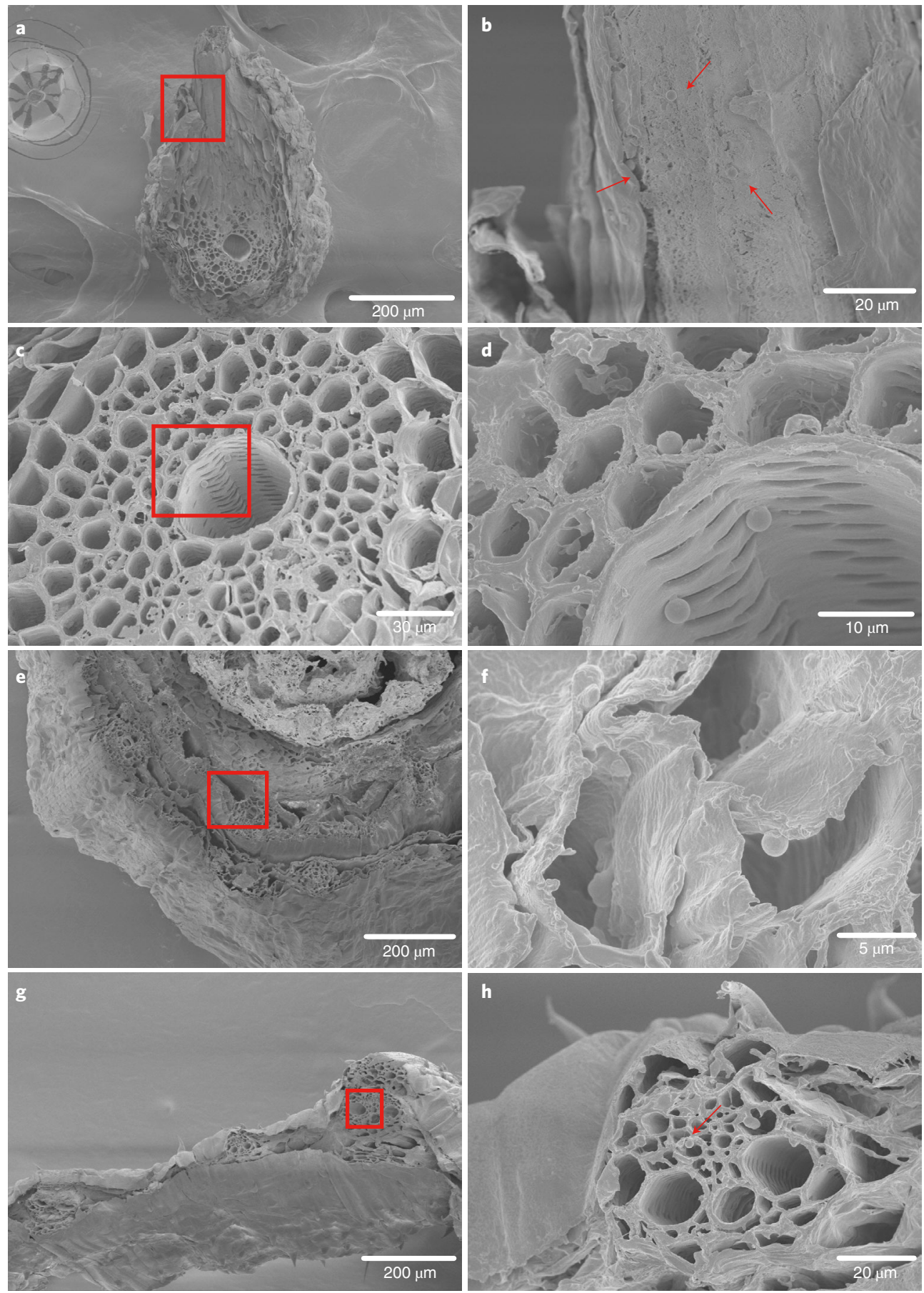

Fig. $\mathbf{5}$ | SEM images of $2.0 \mu \mathrm{m}$ PS microbead localization in the root, stem and leaf of a wheat plant. Two-week-old plants were exposed to $50 \mathrm{mg} \mathrm{l}^{-1}$ suspensions of PS beads for $10 \mathrm{~d}$. $\mathbf{a}, \mathbf{b}$, PS microbeads in the crack between the epidermal tissue of the main wheat root and the secondary root. $\mathbf{c}, \mathbf{d}$, PS microbeads in the xylem vessels and cortical tissue. e,f, PS microbeads in the xylem of the stem. $\mathbf{g}, \mathbf{h}$, PS microbeads in the leaf vein. $\mathbf{b}, \mathbf{d}, \mathbf{f}, \mathbf{h}$ are enlargements of the areas marked by the red squares in $\mathbf{a}, \mathbf{c}, \mathbf{e}, \mathbf{g}$, respectively. $\ln \mathbf{b}$ and $\mathbf{h}$, the red arrows indicate the microbeads.

(over $100 \mathrm{~nm}$ ) can be taken up by plants despite the very small SELs (less than $20 \mathrm{~nm}$ ) of plant roots. Our findings showed the effective accumulation of submicrometre PS particles $(200 \mathrm{~nm})$ in the root. Another study also showed promising results for the root uptake of zein nanoparticles (up to $135 \mathrm{~nm}$; ref. ${ }^{29}$ ). By contrast, the typical upper size limits for inorganic nanoparticles are always up to $50 \mathrm{~nm}$ for root uptake $\mathrm{e}^{30-32}$. Our own experiment using $200 \mathrm{~nm}$ silica fluorescent nanoparticles showed no nanoparticle uptake inside the root tissue, although a few light-red particles adhered to the root surface (Supplementary Fig. 29). This difference in SEL between metal-based particles and polymeric particles may be at least partly attributed to the intrinsic features (density, hydrophobic surface, adhesive properties and mechanical flexibility) of the polymeric particles, which presumably enable irreversible adsorption on the cellulosic cell wall ${ }^{33}$. The root cap can secrete large amounts of mucilage (a highly hydrated polysaccharide) to defend the plant against pathogen attacks ${ }^{34}$. We observed that PS beads were extracellularly trapped in the wheat root cap mucilage (Supplementary 

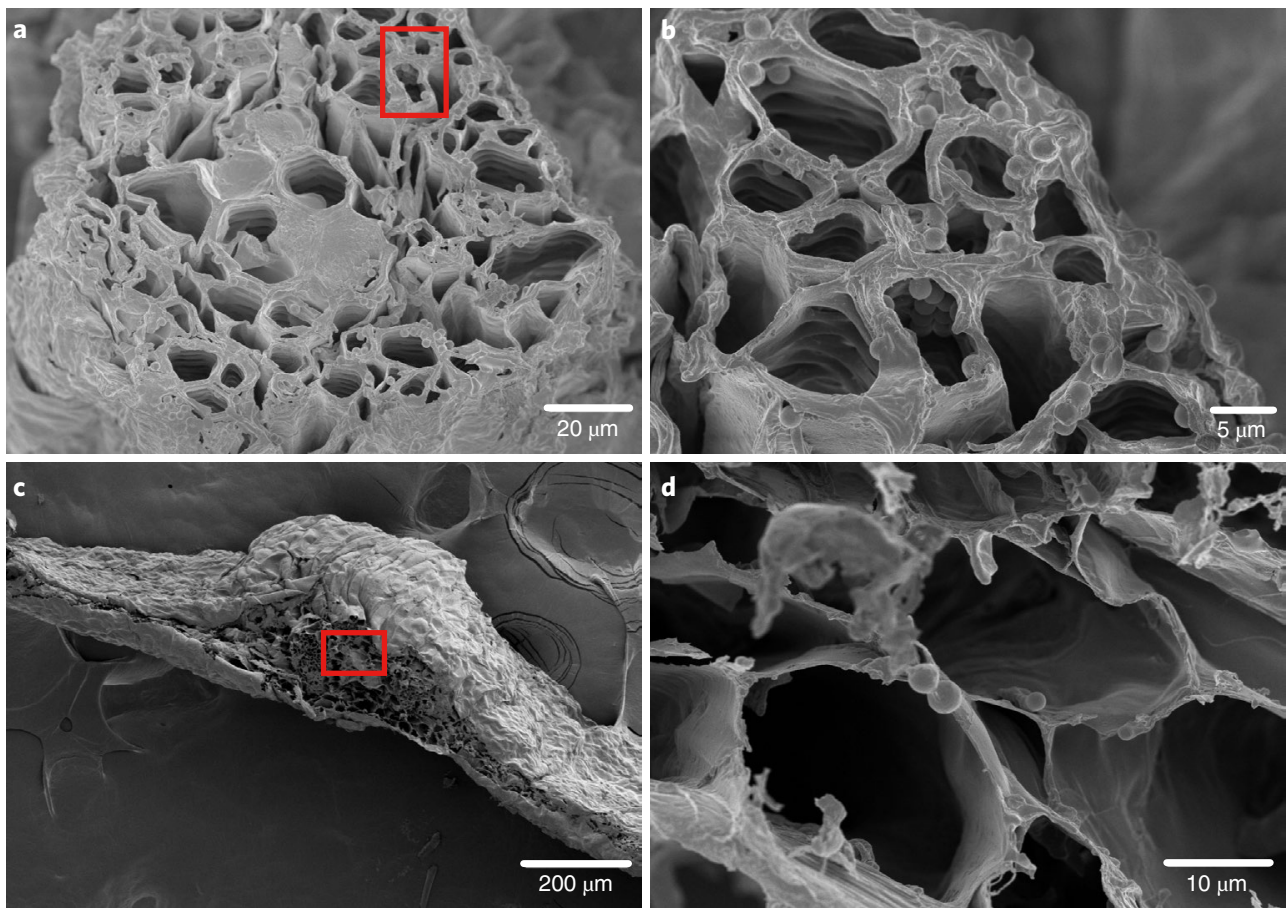

Fig. 6 | SEM images of $2.0 \mu \mathrm{m}$ PS bead localization in the root and leaf of a lettuce plant. One-month-old plants were exposed to $50 \mathrm{mg} \mathrm{l^{-1 }}$ suspensions of PS beads for $10 \mathrm{~d}$. $\mathbf{a}, \mathbf{b}$, Microbeads in the root xylem. $\mathbf{c}, \mathbf{d}$, PS microbeads in the leaf vein. $\mathbf{b}, \mathbf{d}$ are enlargements of the areas marked by the red squares in $\mathbf{a}, \mathbf{c}$, respectively.

Figs. 7 and 8). The negative charges on the bead surface did not prevent interactions with the roots, whose surface and mucilage are also likely to be negatively charged ${ }^{35}$. The washing procedures undertaken before analysis did not remove all the PS beads present on the root surface, demonstrating that the beads adhered strongly to the root surface. Hence, it is proposed that in addition to the role of mucilage, hydrophobic interactions dominate PS bead adhesion at the root surface, owing to the high level of hydrophobicity of both the PS beads and the cellulose cell wall ${ }^{36}$. The PS beads were observed to be deformed in the intercellular space of wheat root during the incorporation process (Supplementary Fig. 32), although it cannot be completely ruled out that the deformation is caused by the SEM sample preparation process. The mechanical strength (Young's modulus) of these PS beads $(2.1 \mathrm{GPa})$ was lower than the values usually reported for plant cell walls (Supplementary Fig. 33, ref. ${ }^{37}$ ). As a result, the PS beads compress and deform on adsorption and intercellular internalization because they are less stiff than the plant cell walls. We suggest that this intrinsic property is essential for the migration of plastic beads within plant tissues, enabling them to reach the root central cylinder and the vascular tissues and resulting in their upward movement to the aerial parts of the plant. The role of the mechanical properties of polymeric nanoparticles in their bio-nano interactions has recently been recognized as a key feature in modulating the fate of polymer nanoparticles for drug delivery ${ }^{38}$.

\section{Tracking methodology for polymeric particles}

Fluorescence labelling and SEM imaging can be used to investigate the localization of plastic beads in plants ${ }^{39}$. Fluorescence tracking of particles is not a perfect technique, but it is one of the best currently available methods for tracking non-metallic nanoparticles. The chemical incorporation of fluorescent dyes into the polymer network minimizes the risk of dye leaching. We have monitored the potential dye leaching from PS and PMMA beads in the exposure medium using a centrifugal ultrafiltration technique over an exposure duration of 10 days. In most cases, no dye leakage was detected in the exposure medium for PMMA beads. Over time, there was only a minimal increase of NBD-Cl release from the PS beads into the solution (Supplementary Fig. 34). Consequently, the presence of fluorescent markers in the aqueous phase can be assumed to be quite negligible. However, it should be noted that in many cases dye leaching in vivo cannot be predicted by in vitro testing using culture media, because the composition of biological fluids outside and inside cells is more complex. Here, the observed fluorescence within the tissue was taken as an initial observation. SEM observation was then used to identify the presence of plastic beads in the plant tissues on the basis of size and morphology, although this method still cannot with full certainty confirm whether the observed particles are actually PS or PMMA.

\section{Exposure and environmental implications}

This study showed the ubiquitous effective root accumulation of different submicrometre plastic particles on exposure to irrigation wastewater. The potential risk of MP uptake via consumption may therefore be substantially greater for root vegetables such as carrots, radishes and turnips. Once MPs enter plant roots, they can translocate to different organs. The extent of the translocation of MPs depends primarily on the transpiration stream, where a compound moves with the water flow through the xylem to the sites of greatest transpiration ${ }^{40}$. Our results confirmed that higher temperature and lower humidity result in greater transpiration rates and thus increased accumulation of beads of different polymer types in the root and upper portions of two crop plants. Furthermore, the presence of MPs in crop plants could increase the direct exposure of humans to plastic-associated chemicals (including leachable additives and adhering contaminants). Lettuce is one of the most consumed vegetables around the world ${ }^{41}$. In the European Union, the daily consumption of $22.5 \mathrm{~g}$ of lettuce per person represents around $6.5 \%$ of the total dietary intake of vegetables ${ }^{42}$. This possibility is of particular concern, especially in the case of lettuce cultivated in 
hydroponic greenhouse systems containing MPs originating from irrigation water and nutrient-rich fertilizer solutions.

Our experiments were performed with MPs concentrations of several $\mathrm{mgl}^{-1}$ to depict the underlying uptake mechanisms. It remains challenging to conclude that the experimental exposures in this study are likely to mimic environmental conditions in terms of MP contamination, since the available analytical methods do not yet permit the accurate detection of nano-sized and even submicrometre-sized plastic particles in the environment. The production, emission and leakage of plastics into the environment are expected to increase by an order of magnitude within the next decade, and MPs concentrations are expected to increase, if only on the basis of the assumption of a steady rate of fragmentation of plastic debris ${ }^{1}$. Despite the fact that the MPs detected in the environment and found in soils are in the range of tens to hundreds of micrometres ${ }^{7,8}$, it is now commonly accepted that plastics present in the environment (including in soils) will be degraded, depending on the environmental conditions, to smaller particles ${ }^{43-46}$. This includes the formation of particles in the low-micrometre to nanometre size range. Here, we tested different sizes of manufactured PS and PMMA beads, which may behave differently from environmental MPs because of differences related to the polymer type, size, coating and shape. Future investigations should therefore include both beads (or other approximately spherical particles) and fibres commonly observed in the environment ${ }^{47}$.

This study revealed the ability of higher plants to accumulate and translocate submicrometre- and micrometre-sized MPs. The results highlight that the crack-entry mode needs to be considered as an important mode of interaction of small MPs with plants. Root openings that develop as a consequence of aging, as well as damage by below-ground herbivores and mechanical injury, might also provide entry sites for MPs. These findings warrant the urgent consideration of new management strategies to control the release of MP waste products in terrestrial environments in discussions of global plastic pollution.

\section{Methods}

PS and PMMA beads. Stock solutions of plain (without functionalization) fluorescently labelled PS and PMMA particles were custom synthesized from Dảe Scientific Co., Ltd. (Tianjin, China) and Rigor Biotechnology Co., Ltd (Wuxi, China). They were supplied as $10 \mathrm{mg} \mathrm{ml}^{-1}$ suspensions in ultrapure water $(18.2 \mathrm{M} \Omega$, Millipore). The PS beads had primary nominal sizes of $\sim 0.2 \mu \mathrm{m}, 2.0 \mu \mathrm{m}, 5.0 \mu \mathrm{m}$, $7.0 \mu \mathrm{m}$ and $10.0 \mu \mathrm{m}$. The actual sizes of the $0.2 \mu \mathrm{m}$ and $2.0 \mu \mathrm{m}$ PS beads were determined to be $0.21 \pm 0.05 \mu \mathrm{m}$ and $1.93 \pm 0.09 \mu \mathrm{m}$ using SEM (Supplementary Fig. $35 \mathrm{a}, \mathrm{b})$. The actual sizes of the $0.2 \mu \mathrm{m}$ and $2.0 \mu \mathrm{m}$ PMMA beads were determined to be $0.18 \pm 0.05 \mu \mathrm{m}$ and $2.0 \pm 0.1 \mu \mathrm{m}$ using SEM (Supplementary Fig. $35 \mathrm{c}, \mathrm{d}$ ). The PS and PMMA beads were prepared on the basis of previously described methods ${ }^{48,49}$. The composition of the beads was confirmed by Raman or infrared spectroscopy (Supplementary Figs. 36 and 37). The Raman spectra of the beads were recorded using a DXR Raman microscope (Thermo Scientific). A $780 \mathrm{~nm}$ laser was focused by a $\times 10$ microscope objective for the sample dried on a glass slide. Infrared spectra were recorded using a Fourier transform infrared spectrometer (FTIR, Nicolet iS5, Thermo Company) equipped with an iD7 ATR accessory and diamond crystal on a single reflection plate. The FTIR was operated with a resolution of $4 \mathrm{~cm}$ and a mid-infrared range of $650-4000 \mathrm{~cm}^{-1}$ at a rate of 32 scans per analysis. All spectra were compared with a database (Hummel Polymers and Additives, Putuzu, Thermo Fisher) to verify the composition of the plastic particles.

The fluorescent dye (NB or NBD-Cl) was chemically incorporated into the polymer network ${ }^{49}$. The labelled beads were centrifuged and washed three times with ethanol and deionized water to remove any free dye. To assess the stability of fluorescence, we analysed the loss of fluorescence intensity after exposure of the PS and PMMA beads in Hoagland solution ${ }^{50}$ or treated wastewater using a centrifugal ultrafiltration technique with an exposure duration of 10 days. In the dye leakage experiment, the centrifugal filter units (Amiconultra, $3 \mathrm{kDa}$ molar mass cut-off) were first pre-equilibrated with the experimental medium used for exposures. Subsequently, $4 \mathrm{ml}$ of each sample were centrifuged at $3,700 \mathrm{~g}$ for $20 \mathrm{~min}$. To ensure that adsorptive losses of dyes were negligible, both the supernatant and the filtrate were discarded, and the protocol was repeated three times. After the fourth centrifugation cycle, potential leaked dyes were determined in the filtrate. In most cases, no dye leakage was detected in the exposure medium for PMMA beads. Over time, there was a minimal increase of NBD-Cl release from the PS beads into the solutions, but the dissolved dye did not exceed 3\% (Supplementary
Fig. 34). The presence of fluorescent markers in the aqueous phase can therefore be assumed to be quite negligible.

The stock suspensions were sonicated for 2 min using a sonicator (Branson Ultrasonic) and were then diluted to obtain the final bead concentrations used in the tests. The average hydrodynamic diameter and zeta potential of the PS and PMMA beads were determined by dynamic laser scattering using a Malvern Zetasizer Nano-ZS90 (ZEN3590). The average hydrodynamic diameters of the $0.2 \mu \mathrm{m}$ and $2.0 \mu \mathrm{m}$ PS beads were $0.25 \pm 0.06 \mu \mathrm{m}$ and $2.3 \pm 0.4 \mu \mathrm{m}$, respectively, while the $0.2 \mu \mathrm{m}$ and $2.0 \mu \mathrm{m}$ PMMA beads were $0.23 \pm 0.05 \mu \mathrm{m}$ and $2.2 \pm 0.3 \mu \mathrm{m}$ in treated wastewater. The surfaces of the PS and PMMA beads were negatively charged, with the $0.2 \mu \mathrm{m}$ PS beads having a more negative zeta potential $(-36.6 \pm 0.7 \mathrm{mV})$ than the PS $2.0 \mu \mathrm{m}$ beads $(-9.3 \pm 0.5 \mathrm{mV})$, and the $0.2 \mu \mathrm{m}$ PMMA beads having a more negative zeta potential $(-26.0 \pm 0.8 \mathrm{mV})$ than the PMMA $2.0 \mu \mathrm{m}$ beads $(-2.1 \pm 0.4 \mathrm{mV})$ in treated wastewater.

Fluorescent silica nanoparticles $(0.2 \mu \mathrm{m})$ were prepared through the covalent encapsulation of a kind of aminocyanine dye inside silica nanoparticles by reverse microemulsion ${ }^{51}$ and were provided by a friend. The particles showed bright and stable fluorescence on excitation at $635 \mathrm{~nm}$. The average hydrodynamic diameters of the particles in Hoagland solution were $0.26 \pm 0.06 \mu \mathrm{m}$.

Plant materials and growth conditions. Seeds of wheat (Triticum aestivum L.) and lettuce (Lactuca sativa L., Rosa) were used in this study. Wheat seeds of an almost uniform size were selected and surface sterilized by treatment with a $10 \% \mathrm{NaClO}$ solution for $5 \mathrm{~min}$. The seeds were then washed three times with deionized water to remove the residual $\mathrm{NaClO}$ solution and were transferred to moistened filter paper and incubated in the dark at $25^{\circ} \mathrm{C}$ to induce germination. After $4 \mathrm{~d}$, four seedlings of uniform size were transferred to a 11 beaker containing Hoagland solution. The beaker was covered with a cap and placed in a growth chamber at $25 \pm 2{ }^{\circ} \mathrm{C}$ with an illumination of $250 \mu \mathrm{mol} \mathrm{m}^{-2} \mathrm{~s}^{-1}$, a $12 \mathrm{~h}$ day $/ 12 \mathrm{~h}$ night photoperiod and $80 \%$ relative humidity. Each box was equipped with an aquarium aerator to provide oxygen to the roots and to keep the PS beads in suspension. After $10 \mathrm{~d}$, the wheat plants were exposed to different concentrations $\left(0.5,5\right.$ and $\left.50 \mathrm{mgl}^{-1}\right)$ of PS beads for up to $10 \mathrm{~d}$. The experiment was repeated three times. Transpiration rates were controlled by placing the plants in one of two environmentally controlled growth chambers maintained at different ambient air water vapour pressure deficits. The water vapour pressure deficit, which is defined as the ratio of the actual air water vapour pressure to the air water vapour pressure at saturation, controls the transpiration rate $^{52}$. The low-transpiration-rate chamber was maintained at a relative humidity of $80 \%$ and a temperature of $15^{\circ} \mathrm{C}$ (a water vapour pressure deficit of 0.9 ). The high-transpiration-rate chamber was maintained at a relative humidity of $50 \%$ and a temperature of $30^{\circ} \mathrm{C}$ (a water vapour pressure deficit of 0.7 ). The night temperature in both chambers was $20^{\circ} \mathrm{C}$, and the daytime relative humidity was maintained. A $12 \mathrm{~h}$ day with a light intensity of $250 \mu \mathrm{mol} \mathrm{m}^{-2} \mathrm{~s}^{-1}$ was used. Stomatal conductance $\left(\mathrm{mol} \mathrm{m}^{-2} \mathrm{~s}^{-1}\right)$ and transpiration rate $\left(\mathrm{mmol} \mathrm{m}^{-2} \mathrm{~s}^{-1}\right)$ were measured using an open photosynthetic system (LI-6400XTR, Li-Cor) at a photon flux density of $1,000 \mu \mathrm{mol} \mathrm{m}^{-2} \mathrm{~s}^{-1}$ and an ambient $\mathrm{CO}_{2}$ concentration of $400 \mu \mathrm{mol} \mathrm{mol}^{-1}$.

Lettuce seeds were surface sterilized with a $10 \% \mathrm{NaClO}$ solution for $5 \mathrm{~min}$ and washed three times with deionized water. The seeds were then germinated and grown in organic soil (potting mix) in a greenhouse (65\% relative humidity) at $25 \pm 2{ }^{\circ} \mathrm{C}$ with a $16 \mathrm{~h}$ day $/ 8 \mathrm{~h}$ night photoperiod for $21 \mathrm{~d}$. The plants were removed from the soil, and the roots were carefully washed with water until no soil was visible on the surface. Two plants were allocated to a 11 beaker containing Hoagland solution and allowed to grow for one week before treatment with PS beads. After one week, the Hoagland solution was replaced with Hoagland solution to which a $50 \mathrm{mgl}^{-1}$ suspension of PS beads had been added. Plants grown in Hoagland solution that lacked a PS bead suspension were used as controls. The plants were grown for $10 \mathrm{~d}$ before the treatments were evaluated. Each treatment was replicated three times.

The fate of the PS beads after addition to a solid matrix was investigated using river sand or a sandy soil. River sand was sieved to obtain particles of less than $2 \mathrm{~mm}$ and washed thoroughly with water before drying and use. The soil was collected in summer 2017, before sowing, from the top layer $(0-20 \mathrm{~cm})$ of a fluvo-aquic soil in Liaocheng, Shandong province, China. The soil had a sandy loam texture (clay $5 \%$, silt $32 \%$ and sand $63 \%$ ), pH 8.2 , total $\mathrm{N} 0.56 \mathrm{gN} \mathrm{kg}^{-1}$ and total organic $\mathrm{C} 8.0 \mathrm{gC} \mathrm{kg}^{-1}$. The cropping rotation system was wheat in winter and maize (Zea mays L.) in summer. Triplicate sand or soil samples $(300 \mathrm{~g})$ were amended with a suspension of PS beads at a target concentration of $150 \mathrm{mg} \mathrm{kg}^{-1}$ sand or $500 \mathrm{mg} \mathrm{kg}^{-1}$ soil, and placed in $800 \mathrm{ml}$ beakers, followed by the addition of deionized water to the sand or soil to $60 \%$ of the water holding capacity. Each beaker was covered and sealed with plastic film with small holes to maintain a relatively constant moisture content; deionized water was added every $4 \mathrm{~d}$ if necessary. The wheat and lettuce seedlings were planted in the sand or soil and incubated in a growth chamber (described above). Samples were collected after $20 \mathrm{~d}$ and immediately washed with deionized water before analysis.

Experiments on plastic bead uptake from treated wastewater. To evaluate plastic bead uptake from real wastewater, the plants were studied further in treated wastewater spiked with MPs and sand matrices irrigated with spiked treated wastewater. Treated wastewater was provided by a local municipal 
wastewater-treatment facility. The treated wastewater characteristics were as follows: biological oxygen demand, $10.0 \mathrm{mgl}^{-1}$; chemical oxygen demand, $40 \mathrm{mgl}^{-1}$; total organic carbon, $56.9 \mathrm{mgl}^{-1}$; total nitrogen, $14.7 \mathrm{mgl}^{-1}$; total phosphorus, $11.9 \mathrm{~g} \mathrm{~g}^{-1} ; \mathrm{pH}, 6.4$; and electrical conductivity, $3.4 \mathrm{mS} \mathrm{cm}^{-1}$. The treated wastewater was filtrated through a $0.45 \mu \mathrm{m}$ membrane and then was used to perform the lettuce uptake experiment in hydroponic cultures spiked with $50 \mathrm{mg}$ of PMMA beads per litre of culture and the wheat uptake experiment in sand culture with a concentration of $150 \mathrm{mg}$ of PS beads per $\mathrm{kg}$ of sand, as described above.

Xylem sap extraction in situ. After exposure to PS beads in hydroponic cultures and sand matrices or a sandy soil as described above, xylem samples were obtained by severing the stems of lettuce and wheat seedlings approximately $5 \mathrm{~cm}$ above the surface of the nutrient solution. After the stem surface had been thoroughly washed with deionized water, the tissues were blotted dry, and the exudate was collected and placed on a glass slide covered with a coverslip. To determine the presence or absence of beads, the slides were examined using an Olympus-CX31 microscope (Olympus).

Confocal microscopy. After exposure to PS or PMMA beads, the roots were removed and washed thoroughly with distilled water. Samples of the roots were collected at different times using separate batches of the two plant species and were then evaluated. Subsequently, fresh root (mature zone) and stem $(2 \mathrm{~cm}$ from the base of the stem) segments were collected and embedded in $4 \%$ agarose. The root and stem samples and the leaf blades (with the primary vein) were sectioned into 40 - and $100-\mu \mathrm{m}$-thick sections, respectively, using a vibrating microtome (VT1200S Vibrotome, Leica). Semithin sample sections were placed on a glass slide and covered with a coverslip. A few drops of PBS were added to keep the sample hydrated. The sectioned tissue was inspected using a confocal laser scanning microscope (FluoView FV1000, Olympus) at excitation/emission wavelengths of $488 / 515 \mathrm{~nm}$ and $635 / 680 \mathrm{~nm}$ for NBD-Cl and NB, respectively. For each species, transverse and longitudinal sections of at least three plants per treatment group were examined before representative images were selected. The images were captured with a SPOT camera and imported into the compound microscope imaging software Fluoview (Olympus FV10-ASW, version 4.2b) (https://www. olympus-lifescience.com.cn/en/support/downloads/). The images were adjusted for brightness and contrast enhancement.

SEM. Samples from roots, stems and fully expanded leaves near the primary veins were excised, sectioned into small pieces and frozen in liquid nitrogen. The samples were then freeze-dried and coated with gold for $60 \mathrm{~s}$ (ca. a $1 \mathrm{~nm}$ thickness of gold) by a sputter coater (Cressington model 108, Ted Pella). The samples were then examined by a scanning electron microscope (SU8010). The cross sections were viewed at an accelerating potential of $20 \mathrm{kV}$ in high vacuum mode with backscatter detection. Images were captured at different magnifications. For each species, at least three plants per treatment group were examined. Digital images were captured using an EVO 40 scanning electron microscope (Zeiss). Lettuce and wheat root samples of the lateral root zone were examined with an environmental scanning electron microscope (FEI Quanta 250 FEG ESEM) operating in high vacuum mode.

X-ray computed microtomography. Root samples of the lateral root zone were scanned using a SkyScan 1172 high-resolution X-ray computed microtomography system (Bruker microCT). The settings were optimized to visualize the gaps between the epidermal cells. The X-ray source was operated at $40 \mathrm{keV}$ without a filter and with a $0.4^{\circ}$ rotation step. A tube of samples was positioned vertically and measured using the oversize scan mode $(2.75 \mathrm{~h}$ per sample). The measured $\mathrm{X}$-ray shadow projections were digitized as $1,800 \times 1,048$ pixel 16-bit images and were processed to obtain reconstructed cross-sectional images using SkyScan NRecon v.1.5.1.4 software (http://www.skyscan.be/next/nreconcluster.zip).

Atomic force microscopy. The mechanical properties of the PS beads were analysed by performing DMT modulus measurements using a Dimension Icon atomic force microscope system (Bruker) in PeakForce quantitative nanomechanical property mapping mode. Images were collected using commercial silicon probes (RTESPA-300, Bruker) and a Stargate scanner (maximum scan size, $100 \mu \mathrm{m}$ ) at a scan rate of $0.5 \mathrm{~Hz}$. The spring constant was calibrated using the thermal tune method. This mode was based on peak force tapping, which performed a very fast force curve measurement for every pixel in the image by modulating the $\mathrm{Z}$ piezo at $\sim 2 \mathrm{kHz}$ with an amplitude of $100 \mathrm{~nm}$. The peak force of each of these curves was then used as the imaging feedback signal. The analysis of the force curve data was performed in real time, providing a map of multiple mechanical properties such as the modulus and adhesion that had a resolution similar to that of the height image.

Reporting Summary. Further information on research design is available in the Nature Research Reporting Summary linked to this article.

\section{Data availability}

The data that support the findings of this study are available in the paper and its Supplementary Information or from the corresponding author upon request.
Received: 22 March 2019; Accepted: 3 June 2020; Published online: 13 July 2020

\section{References}

1. Jambeck, J. R. et al. Plastic waste inputs from land into the ocean. Science 347, 768-771 (2015)

2. Barnes, D. K. A. et al. Accumulation and fragmentation of plastic debris in global environments. Phil. Trans. R. Soc. B 364, 1985-1998 (2009).

3. Wallace, $H$. Presence of microplastics and nanoplastics in food, with particular focus on seafood. EFSA J. 14, e04501 (2016).

4. Wardrop, P. et al. Chemical pollutants sorbed to ingested microbeads from personal care products accumulate in fish. Environ. Sci. Technol. 50 4037-4044 (2016).

5. Rochman, C. M. Microplastics research-from sink to source. Science 360, 28-29 (2018).

6. Seltenrich, N. New link in the food chain? marine plastic pollution and seafood safety. Environ. Health Persp. 123, A34-41 (2015).

7. Nizzetto, L., Langaas, S. \& Futter, M. Pollution: do microplastics spill on to farm soils? Nature 537, 488 (2016).

8. Zhou, Q. et al. The distribution and morphology of microplastics in coastal soils adjacent to the Bohai Sea and the Yellow Sea. Geoderma 322, 201-208 (2018)

9. Weithmann, N. et al. Organic fertilizer as a vehicle for the entry of microplastic into the environment. Sci. Adv. 4, EAAP8060 (2018)

10. Nizzetto, L., Futter, M. \& Langaas, S. Are agricultural soils dumps for microplastics of urban origin? Environ. Sci. Technol. 50, 10777-10779 (2016).

11. van Sebille, E. A global inventory of small floating plastic debris. Environ. Res. Lett. 10, 124006 (2015)

12. Rodriguez-Seijo, A. et al. Histopathological and molecular effects of microplastics in Eisenia andrei Bouché. Environ. Pollut. 220, 495-503 (2017)

13. Huerta Lwanga, E. et al. Field evidence for transfer of plastic debris along a terrestrial food chain. Sci. Rep. 7, 14071 (2017).

14. Sato, T. et al. Global, regional, and country level need for data on wastewater generation, treatment, and use. Agric. Water Manage. 130, 1-13 (2013).

15. Kalčíková, G. et al. Wastewater treatment plant effluents as source of cosmetic polyethylene microbeads to freshwater. Chemosphere 188, 25-31 (2017).

16. Schwab, F. et al. Barriers, pathways and processes for uptake, translocation and accumulation of nanomaterials in plants - critical review. Nanotoxicology 10, 257-278 (2016).

17. Robardsa, W. \& Jackson, M. in Perspectives in Experimental Biology Vol. 2 (ed. Sunderland, N.) 413-422 (Pergamon, 1976).

18. Karas, I. \& Mccully, M. E. Further studies of the histology of lateral root development in Zea mays. Protoplasma 77, 243-269 (1973).

19. Huang, J. Ultrastructure of bacterial penetration in plants. Annu. Rev. Phytopathol. 24, 141-157 (1986).

20. Vega-Hernández, M. C. et al. Novel infection process in the indeterminate root nodule symbiosis between Chamaecytisus proliferus (tagasaste) and Bradyrhizobium sp. New Phytol. 150, 707-721 (2001).

21. Marschner, H. Mineral Nutrition of Higher Plants 2nd edn (Academic, 1995).

22. Carpita, N. et al. Determination of the pore size of cell walls of living plant cells. Science 205, 1144-1147 (1979).

23. Smith, H. The Molecular Biology of Plant Cells (Univ. of California Press, 1978)

24. Enstone, D. E. \& Peterson, C. A. Suberin lamella development in maize seedling roots grown in aerated and stagnant conditions. Plant Cell Environ. 28, 444-455 (2005).

25. Gouin, T. et al. Use of micro-plastics beads in cosmetics products in Europe and their estimated emissions to the North Sea environment. SOFW J. 141, 40-46 (2015).

26. Plastic in Cosmetics (UNEP, 2015).

27. Fendall, L. S. \& Sewell, M. A. Contributing to marine pollution by washing your face: microplastics in facial cleansers. Mar. Pollut. Bull. 58, 1225-1228 (2009).

28. Fahn, A. Plant Anatomy (Pergamon, 1982).

29. Ristroph, K. D. et al. Zein nanoparticles uptake by hydroponically grown soybean plants. Environ. Sci. Technol. 51, 14065-14071 (2017).

30. González-Melendi, P. et al. Nanoparticles as smart treatment-delivery systems in plants: assessment of different techniques of microscopy for their visualization in plant tissues. Ann. Bot. 101, 187-195 (2008).

31. Taylor, A. F. et al. Investigating the toxicity, uptake, nanoparticle formation and genetic response of plants to gold. PLoS ONE 9, e93793 (2014)

32. Larue, C. et al. Accumulation, translocation and impact of $\mathrm{TiO}_{2}$ nanoparticles in wheat (Triticum aestivum spp.): influence of diameter and crystal phase. Sci. Total Environ. 431, 197-208 (2012).

33. Zhang, M. \& Akbulut, M. Adsorption, desorption, and removal of polymeric nanomedicine on and from cellulose surfaces: effect of size. Langmuir 27, 12550-12559 (2011).

34. Wen, F. et al. Extracellular proteins in pea root tip and border cell exudates. Plant Physiol. 143, 773-783 (2007). 
35. Driouich, A. et al. Root border cells and secretions as critical elements in plant host defense. Curr. Opin. Plant Biol. 16, 489-495 (2013).

36. Nel, A. E. et al. Understanding biophysicochemical interactions at the nano-bio interface. Nat. Mater. 8, 543-557 (2009).

37. Wang, C. X. et al. Modelling the mechanical properties of single suspension-cultured tomato cells. Ann. Bot. 93, 443-453 (2004).

38. Yu, M. et al. Rapid transport of deformation-tuned nanoparticles across biological hydrogels and cellular barriers. Nat. Commun. 9, 2607 (2018).

39. Li, L. Z. et al. Uptake and accumulation of microplastics in an edible plant. Chin. Sci. Bull. 64, 928-934 (2019).

40. White, P. J. Long-Distance Transport in the Xylem and Phloem (Elsevier, 2011)

41. Production/Crops (FAO Statistics Division, 2017); http://faostat3.fao.org/ browse/Q/QC/E.

42. GEMS/Food Regional Diets: Regional Per Capita Consumption of Raw and Semi-processed Agricultural Commodities (WHO, 2003).

43. Lehner, R. et al. Emergence of nanoplastic in the environment and possible impact on human health. Environ. Sci. Technol. 53, 1748-1765 (2019).

44. Ter Halle, A. et al. Nanoplastic in the North Atlantic subtropical gyre. Environ. Sci. Technol. 51, 13689-13697 (2017).

45. Lambert, S. \& Wagner, M. Characterisation of nanoplastics during the degradation of polystyrene. Chemosphere 145, 265-268 (2016).

46. Mitrano, D. M. et al. Synthesis of metal-doped nanoplastics and their utility to investigate fate and behaviour in complex environmental systems. Nat. Nanotechnol. 14, 362-368 (2019).

47. Zubris, K. A. V. \& Richards, B. K. Synthetic fibers as an indicator of land application of sludge. Environ. Pollut. 138, 201-211 (2005).

48. Lu, S., Qu, R. \& Forcada, J. Preparation of magnetic polymeric composite nanoparticles by seeded emulsion polymerization. Mater. Lett. 63 770-772 (2009).

49. Peng, B. et al. Synthesis of monodisperse, highly cross-linked, fluorescent PMMA particles by dispersion polymerization. Langmuir 28, 6776-6785 (2012).

50. Hoagland, D. R. \& Arnon, D. I. The Water-Culture Method for Growing Plants without Soil Circular No. 347 (Univ. of California, College of Agriculture, 1938)

51. Jiao, L. et al. Improving the brightness and photostability of NIR fluorescent silica nanoparticles through rational fine-tuning of the covalent encapsulation methods. J. Mater. Chem. B 5, 5278-5283 (2017).
52. Stanghellini, C. \& Van Meurs, W. T. M. Environmental control of greenhouse crop transpiration. J. Agric. Eng. Res. 51, 297-311 (1992).

\section{Acknowledgements}

We acknowledge the financial support by the National Nature Science Foundation of China (grant nos 41877142 and 41991330), the Key Research Program of Frontier Sciences, CAS (grant no. QYZDJ-SSW-DQC015) and the External Cooperation Program of BIC, Chinese Academy of Sciences (grant no. 133337KYSB20160003). We thank P. Christie from the Institute of Soil Science, Chinese Academy of Sciences, China, for contributing to language polishing.

\section{Author contributions}

Y.L. managed the whole project, designed all the experiments and jointly wrote the manuscript. L.L. conducted the uptake experiments and wrote the manuscript. R.L. inspected the plant tissue using a confocal laser scanning microscope and collected the images. N.Y. and J.Y. examined the samples with a scanning electron microscope and collected the images. R.L. and Y.Z. conducted the X-ray computed microtomography using a high-resolution X-ray computed microtomography system. Q.Z. and N.Y. analysed the mechanical properties of the PS beads using a Dimension Icon atomic force microscope system and collected the images. W.J.G.M.P. and C.T. helped with the manuscript revising and data analysis.

\section{Competing interests}

The authors declare no competing interests.

\section{Additional information}

Supplementary information is available for this paper at https://doi.org/10.1038/ s41893-020-0567-9.

Correspondence and requests for materials should be addressed to Y.L.

Reprints and permissions information is available at www.nature.com/reprints.

Publisher's note Springer Nature remains neutral with regard to jurisdictional claims in published maps and institutional affiliations.

(C) The Author(s), under exclusive licence to Springer Nature Limited 2020 


\section{Reporting Summary}

Nature Research wishes to improve the reproducibility of the work that we publish. This form provides structure for consistency and transparency in reporting. For further information on Nature Research policies, see Authors \& Referees and the Editorial Policy Checklist.

\section{Statistics}

For all statistical analyses, confirm that the following items are present in the figure legend, table legend, main text, or Methods section.

$\mathrm{n} / \mathrm{a}$ | Confirmed

$\square \bigotimes$ The exact sample size $(n)$ for each experimental group/condition, given as a discrete number and unit of measurement

$\square$ \ A statement on whether measurements were taken from distinct samples or whether the same sample was measured repeatedly

$\square$ The statistical test(s) used AND whether they are one- or two-sided

$\square$ Only common tests should be described solely by name; describe more complex techniques in the Methods section.

Х $\square$ A description of all covariates tested

Х $\square$ A description of any assumptions or corrections, such as tests of normality and adjustment for multiple comparisons

$\square$ A full description of the statistical parameters including central tendency (e.g. means) or other basic estimates (e.g. regression coefficient)

$\square$ AND variation (e.g. standard deviation) or associated estimates of uncertainty (e.g. confidence intervals)

For null hypothesis testing, the test statistic (e.g. $F, t, r$ ) with confidence intervals, effect sizes, degrees of freedom and $P$ value noted

$\triangle$ Give P values as exact values whenever suitable.

Х $\square$ For Bayesian analysis, information on the choice of priors and Markov chain Monte Carlo settings

Х $\square$ For hierarchical and complex designs, identification of the appropriate level for tests and full reporting of outcomes

Х $\square$ Estimates of effect sizes (e.g. Cohen's $d$, Pearson's $r$ ), indicating how they were calculated

Our web collection on statistics for biologists contains articles on many of the points above.

\section{Software and code}

Policy information about availability of computer code
Data collection
No software was used.

Data analysis

No software was used.

For manuscripts utilizing custom algorithms or software that are central to the research but not yet described in published literature, software must be made available to editors/reviewers. We strongly encourage code deposition in a community repository (e.g. GitHub). See the Nature Research guidelines for submitting code \& software for further information.

\section{Data}

Policy information about availability of data

All manuscripts must include a data availability statement. This statement should provide the following information, where applicable:

- Accession codes, unique identifiers, or web links for publicly available datasets

- A list of figures that have associated raw data

- A description of any restrictions on data availability

All data are reported in the paper or the supplementary materials.

\section{Field-specific reporting}

Please select the one below that is the best fit for your research. If you are not sure, read the appropriate sections before making your selection.
Life sciences
$\square$ Behavioural \& social sciences
$\bigotimes$ Ecological, evolutionary \& environmental sciences

For a reference copy of the document with all sections, see nature.com/documents/nr-reporting-summary-flat.pdf 


\section{Ecological, evolutionary \& environmental sciences study design}

All studies must disclose on these points even when the disclosure is negative.

Study description

Here, we aim to determine whether crop plants wheat and lettuce growing in hydroponic systems and sand matrices or a sandy soil are able to take up PS or PMMA plastic beads (ranging from submicrometer- to micrometer-sized) from nutrient solution and wastewater and translocate these particles from roots to shoots, and if so, to identify the uptake sites and pathways. Plants grown in solution that lacked plastic beads suspension were used as controls. Each treatment was replicated at least three times.

Research sample Wheat was chosen as a representative of monocot plants because it is one of the main staple foods worldwide; lettuce was selected as a representative of dicot plants because it is a popular leafy vegetable. Seeds of wheat (Triticum aestivum L.,) and lettuce (Lactuca sativa L., Rosa) were provided by academy of agricultural sciences.

Sampling strategy

To identify the uptake mechanism and pathways of microplastic by the plants, for each species, transverse and longitudinal sections of six plants per treatment group were examined by confocal microscopy before representative images were selected. For each species, six plants per treatment group were examined using Scanning Electron Microscopy.

Data collection

The third and sixth author inspected the plant tissue using a confocal laser scanning microscope and collected the images. The fourth and seventh author examined the samples by a scanning electron microscope and collected the image. X-ray computed microtomography $(\mu-C T)$ was conducted by the third author using a high-resolution X-ray $\mu$-CT system. The sixth author analyzed the mechanical properties of the PS beads using a Dimension Icon atomic force microscope system and collected the images.

Timing and spatial scale The study were conducted during the periods from November 2017 to March 2020. The data was collected in the same place in our study.

Data exclusions

No data was excluded from analyses in our study.

Reproducibility

For each experiment, all attempt to repeat the experiment were successful.

Randomization

In the experiment, each specie of plants were allocated into different groups randomly.

Blinding

Blinding was used during the data acquisition and analysis in our study.

Did the study involve field work? $\square$ Yes $\square$ No

\section{Reporting for specific materials, systems and methods}

We require information from authors about some types of materials, experimental systems and methods used in many studies. Here, indicate whether each material, system or method listed is relevant to your study. If you are not sure if a list item applies to your research, read the appropriate section before selecting a response.

Materials \& experimental systems

$\mathrm{n} / \mathrm{a}$ Involved in the study

\ $\square$ Antibodies

\ $\square$ Eukaryotic cell lines

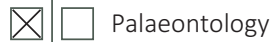

$\bigotimes \square$ Animals and other organisms

$\bigotimes \square$ Human research participants

$\bigotimes \square$ Clinical data

\begin{tabular}{l|l} 
Methods \\
\hline n/a & Involved in the study \\
$\square$ & $\square$ ChIP-seq \\
$\square$ & $\square$ Flow cytometry \\
$\square$ & $\square$ MRI-based neuroimaging
\end{tabular}

